\title{
MORFOLOGIA E ASPECTOS HIDROLÓGICOS DA BACIA HIDROGRÁFICA DO RIO PRETO, DIVISA DOS ESTADOS DO RIO DE JANEIRO E DE MINAS GERAIS ${ }^{1}$
}

\author{
Nelci Olszevski², Elpidio Inácio Fernandes Filho ${ }^{3}$, Liovando Marciano da Costa ${ }^{3}$, Carlos Ernesto \\ Gonçalves Reynaud Schaefer ${ }^{3}$, Eliana de Souza ${ }^{4}$ e Oldair Del'Arco Vinhas Costa ${ }^{5}$

\begin{abstract}
RESUMO - Neste trabalho, determinaram-se as características morfométricas do relevo e da rede de drenagem da Bacia Hidrográfica do Rio Preto, com a finalidade de prever do comportamento hidrológico da área. A partir da delimitação da área da bacia, da digitalização das curvas de nível e do sistema de drenagem, foram obtidas características geométricas do relevo e da hidrografia da BHRP e das suas seis sub-bacias. Concluiu-se que a área apresentava forma alongada e estreita, aliada a uma alta densidade de drenagem, evidenciando menor possibilidade de ocorrência de cheias. Porém, foram observadas enchentes justificadas pelos solos rasos, pelos intensos processos de desmatamento e uso da terra e pelo relevo acidentado, sendo 73,1\% da área caracterizada como de relevo forte-ondulado a montanhoso. Quanto às sub-bacias, verificou-se que em todas essas unidades
\end{abstract} \\ menos de 28\% da área era compreendida de relevo plano, facilitando a erosão hídrica.
}

Palavras-chave: Conservação solo, Sistemas de informações geográficas e Hidrografia.

\section{MORPHOLOGY AND HYDROLOGICAL ASPECTS OF BLACK RIVER BASIN, DIVISION OF STATE OF RIO DE JANEIRO AND MINAS GERAIS}

\begin{abstract}
It was determined in this work the morphometric characteristics of relief and drainage system of Rio Preto Watershed (RPW) to predict the area hydrological behavior. From delimitation of the watershed area, digitalization of the contour lines and from the drainage system, it was obtained the geometrical traits of the relief and RPW hydrography its six main sub-watersheds. It was concluded that the area presented elongated and narrow shape together with a high drainage density, evidencing lower risk of flood occurrence. On the other hand, it was observed floods justified by shallow soils caused by the intense process of deforestation and land use and by the rugged relief, with $73.1 \%$ of the area characterized from rugged relief to mountainous. Regarding the sub-watersheds, it was observed that less than $28 \%$ of the area was comprised by flat relief, facilitating water erosion.
\end{abstract}

Keywords: Soil conservation, Geographics informations systems and Hydrography.

\section{INTRODUÇÃO}

Com o advento dos Sistemas de Informações Geográficas, as informações morfológicas e hidrológicas de uma área, úteis em aplicações como modelagem de fluxos hidráulicos, transporte e deposição de poluentes e predição de inundações (CEBALLOS; SCHNABEL, 1998), podem ser obtidas através do processo de modelagem, com a geração, por exemplo, dos modelos digitais de elevação hidrologicamente consistentes (MDEHC). Um MDEHC é definido como "a melhor representação digital do terreno (no formato matricial ou TIN - triangular irregular network) capaz de reproduzir com exatidão o caminho preferencial de escoamento da água superficial observado no mundo real" (ESRI,

\footnotetext{
${ }^{1}$ Recebido em 10.04.2010 e aceito para publicação em 14.04.2011

${ }^{2}$ Fundação Universidade Federal do Vale do São Francisco, UNIVASF, Brasil. E-mail: <nelci.olszevski@univasf.edu.br>. ${ }^{3}$ Departamento de Solos, Universidade Federal de Viçosa, UFV, Brasil. E-mail: <elpidio@ufv.br>, <liovando.costa@ufv.br> e <carlos.schaefer@ufv.br>.

${ }^{4}$ Programa de Pós-Graduação em Solos pela Universidade Federal de Viçosa, UFV, Brasil. E-mail: <elianadsouza@yahoo.com.br>. ${ }^{5}$ Professor adjunto do Centro de Ciências Agrárias, Ambientais e Biológicas da Universidade Federal do Recôncavo da Bahia UFRB. E-mail: <oldair@ufrb.edu.br>.
} 
1997). A partir da sua geração podem ser derivadas características e índices físicos de uma bacia hidrográfica de forma mais precisa. Até pouco tempo atrás, tais características eram obtidas através do exame das curvas de nível e da rede de drenagem das bases cartográficas e, manualmente, realizavam-se a interpretação e delimitação de seus limites, e uso de modelos, que requeriam medidas precisas, era questionado (WANG; YIN, 1998).

Para investigar as características das diversas formas de relevo, as bacias hidrográficas se configuram como feições importantes, principalmente no que se refere aos estudos de evolução do modelado da superfície terrestre. Entretanto, a maioria dos trabalhos científicos acerca de bacias hidrográficas evidencia qualitativamente os aspectos de forma que, em geral, é insuficiente para a identificação de homogeneidades, no que diz respeito aos fatores que influenciam as formas de relevo. Assim, é evidente a necessidade do emprego de métodos quantitativos para estudos desta natureza (ALVES; CASTRO, 2003).

Para Soares (2000), o movimento de água depende fundamentalmente da configuração da bacia e tem como principais características, segundo Vilela e Matos (1975), a forma, as dimensões, o sistema de drenagem e o relevo. Nesse caso, incluem-se: área, perímetro, comprimento do curso d'água principal, coeficiente de compacidade, fator de forma, ordem dos cursos d'água, declividade média da bacia, elevação média da bacia e declividade entre a foz e a nascente, sendo essencial seu conhecimento para o estabelecimento de estratégias de manejo.

Área de drenagem é definida como a área plana delimitada pelo divisor de águas, sendo fundamental para definir a potencialidade hídrica da bacia hidrográfica (GARCEZ; ALVAREZ, 1988). O coeficiente de compacidade (Kc) é a relação entre o perímetro da bacia e a circunferência de um círculo de área igual à da bacia, sendo um número adimensional que varia com a forma da bacia, independentemente do seu tamanho. Quanto mais irregular for a bacia, tanto maior será o coeficiente de compacidade e, se os outros fatores forem iguais, a tendência para maiores picos de enchentes é tanto mais acentuada quanto mais próximo da unidade for esse número. $\mathrm{O}$ fator de forma (Kf) relaciona a largura média e o comprimento axial da bacia e constitui outro índice indicativo da tendência para enchentes. Uma bacia com Kf baixo, isto é, estreita e longa, é menos sujeita a enchentes que outra de mesmo tamanho, porém com maior Kf, pois há menor possibilidade de ocorrência de chuvas intensas cobrindo simultaneamente toda a sua extensão (VILELA; MATOS, 1975). A densidade de drenagem (Dd) fornece indicação do grau de desenvolvimento de um sistema de drenagem. Como a densidade de drenagem varia inversamente com a extensão do escoamento superficial, ela fornece indicação sobre a eficiência de drenagem na bacia. Esse escoamento é expresso pela relação entre o comprimento total de todos os cursos d'água (Lt) de uma bacia e sua área total (A), variando de 0,5 para bacias com drenagem pobre a 3,5 ou mais para bacias excepcionalmente bem drenadas (VILELA; MATOS, 1975). A extensão média do escoamento superficial (l) é definida como a distância em que a água da chuva teria que escoar sobre os terrenos de uma bacia, caso o escoamento ocorresse em linha reta desde onde caiu até o ponto mais próximo no leito de um curso d'água qualquer da bacia (VILELA; MATOS, 1975). Embora a extensão média do escoamento superficial que efetivamente ocorre sobre os terrenos possa ser bastante diferente dos valores determinados por equações, devido a fatores de influências, esse índice constitui indicação da distância média do escoamento superficial (VILELA; MATOS, 1975). Aordem dos cursos d'água é uma classificação que reflete o grau de ramificação dentro de uma bacia. São consideradas de primeira ordem as correntes formadoras, ou seja, os pequenos canais que não tenham tributários; quando dois canais de primeira ordem se unem, é formado um segmento de segunda ordem; a junção de dois rios de segunda ordem dá lugar à formação de um rio de terceira ordem, e assim sucessivamente: dois rios de ordem "n" dão lugar a um rio de ordem " $n+1$ " (HORTON, 1945 citado por VILELA; MATOS, 1975).

A descrição de características morfológicas e hidrológicas de uma bacia hidrográfica, aliada ao conhecimento do uso do solo, auxilia, desse modo, o processo de avaliação de possíveis efeitos de perturbação das características do ecossistema em suas condições naturais de equilíbrio, visando estabelecer parâmetros adequados de exploração pelo homem. Esse processo de exploração adequada visa ao desenvolvimento sustentável, conservando os recursos genéticos, não degradando o meio ambiente e sendo apropriado tecnicamente, viável economicamente e aceitável socialmente (FAO, 1990). 
De acordo com Bie et al. (1996), a degradação das terras é frequentemente induzida por atividades humanas, e os principais fatores para a degradação ambiental são as práticas agrícolas inadequadas, incluindo superpastoreio, desmatamento e superexploração dos recursos florestais para fins energéticos. Assim, os estudos a respeito da capacidade de suporte têm-se mostrado como ferramentas importantes e aumentado o conhecimento a respeito da potencialidade e da sustentabilidade das terras em nível regional (BIE et al., 1996).

Para o caso da área em estudo, denominada Bacia Hidrográfica do Rio Preto, segundo Ceivap (2001), nas últimas décadas do século XVIII teve início a segunda grande monocultura agrícola de exportação no país - o café -, expandindo-se a partir dos núcleos de apoio das rotas de exploração de minérios do interior, entre os Estados do Rio de Janeiro, de São Paulo e Minas Gerais. Tal como a cana de açúcar, a cafeicultura desenvolveu-se sob um "tripé colonial": monocultura, latifúndio e trabalho escravo, em que o cuidado com o que hoje se chama de capacidade de uso das terras era absolutamente inexistente. O modo inadequado de cultivo do café em linhas ao longo das encostas em uma região de relevo predominantemente acidentado levou a cafeicultura rapidamente à decadência, reduzindo a extensão e a importância econômica do café em menos de um século de exploração. Enquanto avançava a decadência da cafeicultura, a pecuária se desenvolvia, substituindo a agricultura como atividade econômica principal até meados do século XX, quando o país entra na era industrial, transformando a região de uma condição de economia e população essencialmente rurais para uma condição predominantemente urbana, em menos de três décadas.

Assim, o objetivo deste trabalho foi a determinação de características morfométricas, do relevo e da rede de drenagem da Bacia Hidrográfica do Rio Preto, com a finalidade de prever o comportamento hidrológico da área.

\section{MATERIAL E MÉTODOS}

\subsection{Localização da área}

A área deste estudo abrange a Bacia Hidrográfica do Rio Preto, pertencente à Bacia Hidrográfica do Rio Paraíba do Sul, abrangendo parte dos Estados de Minas Gerais e do Rio de Janeiro (Figura 1).

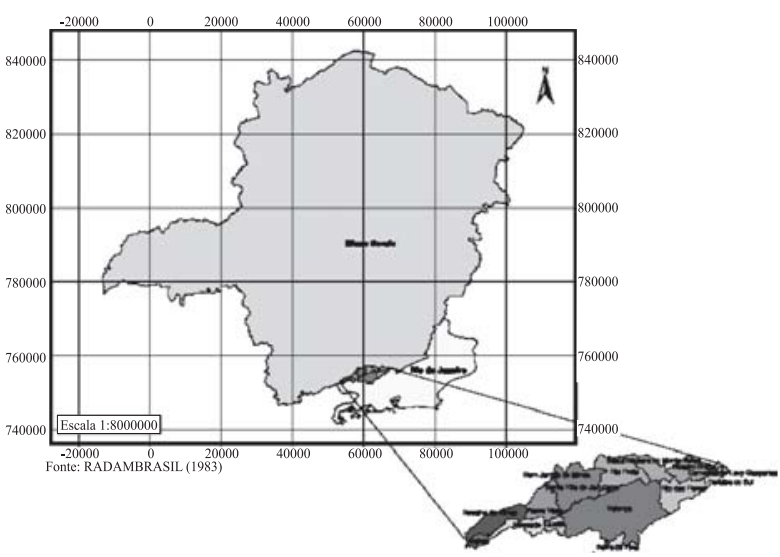

Figura 1 - Distribuição espacial e limites geográficos dos municípios da BHRP, nos Estados de Minas Gerais e do Rio de Janeiro.

Figure 1 - Spatial distribution and geographic limits of municipalities of Rio Preto Watershed in Minas Gerais and Rio de Janeiro States.

\subsection{Geração do Modelo Digital de Elevação Hidrologicamente Consistente (MDEHC)}

A partir de 15 cartas topográficas na escala 1:50.000, pertencente à base de dados do IBGE, foram digitalizadas as curvas de nível (20 em 20 m) e a hidrografia da área de interesse. As cartas utilizadas foram: Alagoa (Mapa índice - 2712-2), Agulhas Negras (2712-4), Liberdade (2713-1), Santa Rita de Jacutinga (2713-2), Resende (2713-3), Nossa Senhora do Amparo (2713-4), Rio Preto (2714-1), Valença (2714-2), Barra do Piraí (2714-3), Vassouras (2714-4), Bom Jardim de Minas (2679-4), Lima Duarte (2680-3), Santa Bárbara do Monte Verde (2680-4), Matias Barbosa (2681-3) e Paraíba do Sul (2715-1).

Tais cartas foram digitalizadas utilizando mesa digitalizadora Summergrid IV, através do modo Edit do software ARC/INFO. Para a geração do Modelo Digital de Elevação (MDE) foram criados arquivos individuais contendo o limite da área de trabalho, a hidrografia digital, o contorno dos lagos e os dados de altimetria discriminados em curvas de nível cotadas. O MDE foi criado a partir da interpolação das curvas de nível digitalizadas e do limite da área da bacia, através do comando Surface - Create TIN from Features do software ARC/VIEW 3.2. Para que o MDE, criado no formato TIN (triangular irregular network), fosse considerado Hidrologicamente Consistente, foi realizada a correção (eliminação) das chamadas depressões espúrias. Tais depressões são células cercadas por 
outras com maiores valores de cota. Para tal, utilizou-se o software ARC/INFO, implementando o módulo ARC e o comando Topogrid. O modelo de elevação foi utilizado para o cálculo da declividade do terreno.

\subsection{Morfologia da Bacia}

De posse da delimitação da área da bacia e de características da rede de drenagem, foram obtidas as características geométricas, do relevo e hidrográficas para a BHRP.

\section{Características geométricas}

- Área total da Bacia (A) e o Perímetro (P): obtidos a partir da tabela de atributos do tema "Limite da Bacia", após a definição da unidade em $\mathrm{km}^{2}$, na opção "View Properties".

- Coeficiente de compacidade (Kc): determinado a partir da equação (VILELA; MATOS, 1975):

$$
K c=0,28(P / \sqrt{A}) \quad \text { eq. } 1
$$

em que:

$$
\begin{aligned}
& \mathrm{P}=\text { perímetro; e } \\
& \mathrm{A}=\text { área }
\end{aligned}
$$

- Fator de forma (Kf): determinado a partir da equação (VILELA; MATOS, 1975):

$$
K f=\left(A / L^{2}\right)
$$

em que:

$$
\begin{aligned}
& \mathrm{A} \text { = área; e } \\
& \mathrm{L}=\text { comprimento do curso d'água principal. }
\end{aligned}
$$

\section{Características do relevo}

- Declividade média (Sm): obtida a partir do MDE do terreno com a criação de seis classes de declividade, de acordo com Embrapa (1999), sendo, então, conhecido o tamanho da área ocupada por cada classe, através do comando Analysis - Tabulate Areas. As classes de declividade foram: 0-3\%, 3-8\%, 8-20\%, $20-45 \%$, 45-75\% e maior do que $75 \%$.

- Declividade entre a foz e a nascente (S1): obtida dividindo-se a diferença total de elevação do leito do rio principal pela extensão horizontal do curso d'água entre a nascente e a seção de referência, ou seja:

$$
S 1=\left(\text { Cota }_{\text {máx }}-\text { Cota }_{\text {mín. }}\right) / L \quad \text { eq. } 3
$$

Revista Árvore, Viçosa-MG, v.35, n.3, p.485-492, 2011 em que:

$$
\mathrm{L} \text { = comprimento do curso d'água principal. }
$$

\section{Características da rede de drenagem}

- Ordem dos cursos d'água: critério de classificação introduzido por Horton (1945 citado por VILELA; MATOS, 1975).

- Comprimento do curso d'água principal (L): obtido a partir da tabela de atributos do tema "Rio Principal", após a definição da unidade em km, na opção "View Properties”.

- Comprimento total dos cursos d'água (Lt): obtido a partir da tabela de atributos do tema "Hidrografia”, após a definição da unidade em km, na opção "View Properties”.

- Densidade de drenagem (Dd): expressa pela relação entre o comprimento total de todos os cursos d'água (Lt) e a área total (A) (equação 4), onde este índice varia de 0,5 para bacias com drenagem pobre a 3,5 ou mais para bacias excepcionalmente bem drenadas (VILELA; MATOS, 1975).

$$
D d=L t / A
$$$$
\text { eq. } 3
$$

em que:

$$
\begin{aligned}
& \mathrm{A} \text { = área; e } \\
& \text { Lt = comprimento total dos cursos d'água. }
\end{aligned}
$$

- Extensão média do escoamento superficial (l): determinada a partir da equação 5 (VILELA; MATOS, 1975).

$$
l=A / 4 L t \quad \text { eq. } 3
$$

em que:

$$
\begin{aligned}
& \text { A = área; e } \\
& \text { Lt = comprimento total dos cursos d’água. }
\end{aligned}
$$

\section{RESULTADOS}

\subsection{Relevo}

As cotas das curvas de nível da BHRP variam de 340 m a 2.787 m, no deságue do Rio Preto no Rio Paraibuna e nascente do Rio Preto, localizada no Parque Nacional do Itatiaia (Pico das Agulhas Negras), respectivamente (Figura 2).

Foram obtidas as classes de declividade para a BHRP e para cada sub-bacia, com as respectivas áreas (Tabela 1). 


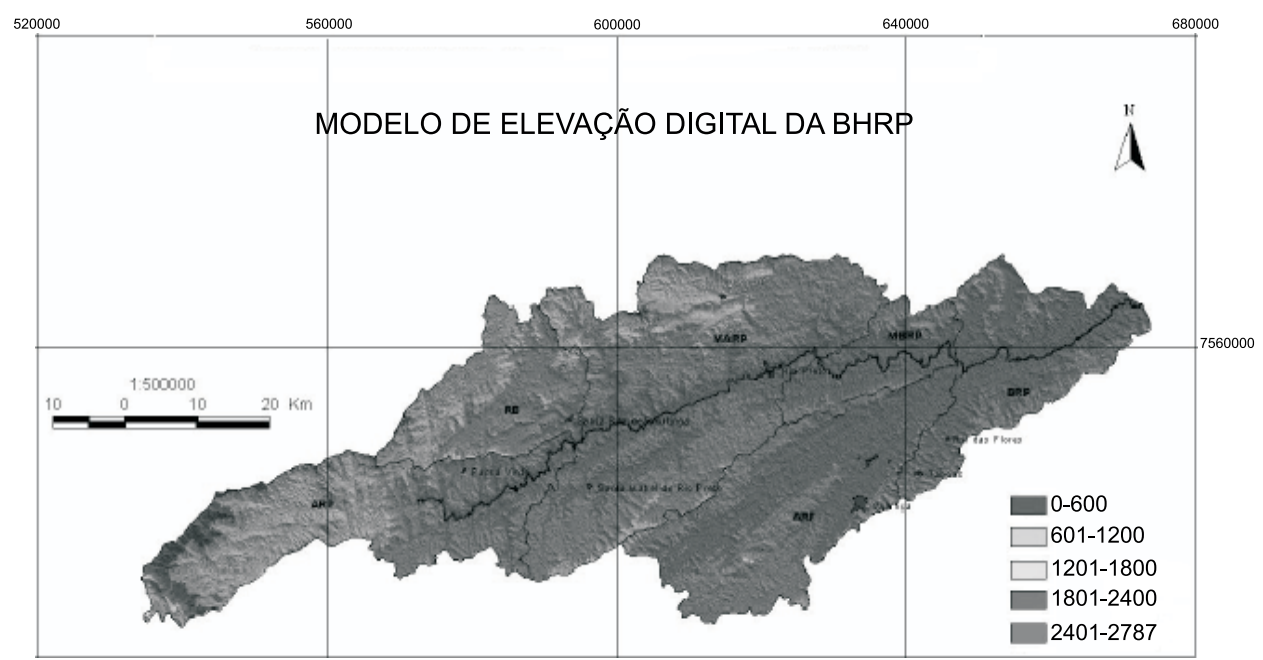

Figura 2 - MDE da BHRP com as respectivas classes de declividade e suas sub-bacias.

Figure 2 - Elevation digital model of the Rio Preto Watershed with slope categories and its sub-watersheds.

Tabela 1 - Área ocupada por cada classe de declividade da BHRP e de cada sub-bacia

Table 1-Area occupied by each slope class on the Rio Preto Watershed and its sub-watersheds

\begin{tabular}{|c|c|c|c|c|c|c|c|c|c|c|c|c|c|c|}
\hline \multirow{2}{*}{$\begin{array}{l}\text { Classes de } \\
\text { declividade } \\
\text { (\%) }\end{array}$} & \multicolumn{2}{|c|}{ BHRP } & \multicolumn{2}{|c|}{ ARP } & \multicolumn{2}{|c|}{$\mathrm{RB}$} & \multicolumn{2}{|c|}{ MARP } & \multicolumn{2}{|c|}{ ARF } & \multicolumn{2}{|c|}{ MBRP } & \multicolumn{2}{|c|}{ BRP } \\
\hline & $\begin{array}{l}\text { Área } \\
\left(\mathrm{km}^{2}\right)\end{array}$ & $\begin{array}{c}\% \text { do } \\
\text { toal }\end{array}$ & $\begin{array}{l}\text { Área } \\
\left(\mathrm{km}^{2}\right)\end{array}$ & $\begin{array}{l}\% \text { do } \\
\text { total }\end{array}$ & $\begin{array}{l}\text { Área } \\
\left(\mathrm{km}^{2}\right)\end{array}$ & $\begin{array}{l}\% \text { do } \\
\text { total }\end{array}$ & $\begin{array}{l}\text { Área } \\
\left(\mathrm{km}^{2}\right)\end{array}$ & $\begin{array}{l}\% \text { do } \\
\text { total }\end{array}$ & $\begin{array}{l}\text { Área } \\
\left(\mathrm{km}^{2}\right)\end{array}$ & $\begin{array}{l}\% \text { do } \\
\text { total }\end{array}$ & $\begin{array}{l}\text { Área } \\
\left(\mathrm{km}^{2}\right)\end{array}$ & $\begin{array}{l}\% \text { do } \\
\text { total }\end{array}$ & $\begin{array}{l}\text { Área } \\
\left(\mathrm{km}^{2}\right)\end{array}$ & $\begin{array}{l}\% \text { do } \\
\text { total }\end{array}$ \\
\hline $0-3$ & 218,26 & 6,35 & 25,08 & 3,68 & 38,54 & 10,65 & 172,98 & 15,73 & 115,86 & 17,75 & 44,13 & 21,28 & 15,88 & 3,66 \\
\hline $3-8$ & 154,68 & 4,50 & 48,61 & 7,13 & 91,84 & 25,38 & 165,17 & 15,02 & 138,77 & 21,26 & 52,84 & 25,48 & 107,27 & 24,73 \\
\hline $8-20$ & 503,55 & 14,65 & 243,86 & 35,77 & 175,18 & 48,41 & 220,05 & 20,01 & 196,54 & 30,11 & 51,99 & 25,07 & 225,99 & 52,10 \\
\hline $20-45$ & 1627,18 & 47,34 & 271,68 & 39,85 & 53,05 & 14,66 & 350,80 & 31,90 & 197,85 & 30,31 & 57,26 & 27,61 & 84,50 & 19,48 \\
\hline $45-75$ & 887,83 & 25,83 & 70,70 & 10,37 & 3,18 & 0,88 & 181,34 & 16,49 & 3,72 & 0,57 & 1,17 & 0,56 & 0,13 & 0,03 \\
\hline$>75$ & 45,71 & 1,33 & 21,82 & 3,20 & 0,00 & 0,00 & 9,36 & 0,85 & 0,00 & 0,00 & 0,00 & 0,00 & 0,00 & 0,00 \\
\hline Área $\left(\mathrm{km}^{2}\right)$ & 3437,22 & & 681,75 & & 361,87 & & 1099,70 & & 652,74 & & 207,39 & & 433,77 & \\
\hline
\end{tabular}

BHRP = Bacia Hidrográfica do Rio Preto; ARP = Sub-bacia do Alto Rio Preto; RB = Sub-bacia do Rio do Bananal; $\mathbf{M A R P}$ = Sub-bacia do Médio Alto Rio Preto; ARF = Sub-bacia do Alto Rio das Flores; $\mathbf{M B R P}$ = Sub-bacia do Médio Baixo Rio Preto; e BRP = Sub-bacia do Baixo Rio Preto.

\section{2. Índices morfométricos e hidrografia}

A BHRP é bem servida por cursos d'água, fato que pode ser confirmado a partir dos índices morfométricos apresentados na Tabela 2. A estimativa desses índices e o conhecimento das vazões máximas associadas a determinado risco de ocorrência são importantes para a determinação de áreas sujeitas à inundação, sendo fundamental a adoção de medidas estruturais e não estruturais para controle ou atenuação do efeito das cheias, fornecendo, também, parâmetros necessários ao entendimento de problemas relacionados à erosão e depósito de material sólido carreado pelas águas (EUCLYDES; FERREIRA, 2002).

\section{DISCUSSÃO}

\subsection{Relevo}

A magnitude dos picos de enchentes, a oportunidade de infiltração e a suscetibilidade à erosão dos solos dependem da rapidez com que ocorre o escoamento sobre os terrenos da bacia (VILELA; MATOS, 1975), tendo relação direta com a declividade, somada a características de solo e de vegetação. Setenta e três vírgula um por cento da área da BHRP estava compreendida entre o relevo forte-ondulado $(47,3 \%)$ e montanhoso (25,8\%), correspondendo a uma área de $2.513 \mathrm{~km}^{2}$, e o restante da área, em torno de $922 \mathrm{~km}^{2}$ (27\%), localizava-se em relevo plano, suave-ondulado

Revista Árvore, Viçosa-MG, v.35, n.3, p.485-492, 2011 
Tabela 2 - Índices morfométricos calculados para a BHRP e as sub-bacias hidrográficas.

Table 2 - Morphometric indices calculated for Rio Preto Watershed and its sub-watersheds.

\begin{tabular}{|c|c|c|c|c|c|c|c|c|c|c|}
\hline \multicolumn{11}{|c|}{ Índices } \\
\hline \multirow{2}{*}{ Local } & Área & $\mathrm{P}$ & $\mathrm{L}$ & $\mathrm{Kc}$ & Kf & $\mathrm{Lt}$ & Dd & l & S1 & \multirow{2}{*}{ Ordem } \\
\hline & $\mathrm{km}^{2}$ & $\mathrm{~km}$ & adm. & adm. & adm. & $\mathrm{km}$ & $\mathrm{km} / \mathrm{km}^{2}$ & $\mathrm{~km}$ & $\mathrm{~m} / \mathrm{m}$ & \\
\hline BHRP & $3.434,57$ & 417,04 & 224,16 & 1,99 & 0,068 & 7534,42 & 2,19 & 0,114 & 0,0020 & 6 \\
\hline ARP & 681,75 & 182,52 & 105,62 & 1,96 & 0,061 & 1602,00 & 2,35 & 0,106 & 0,0220 & 5 \\
\hline $\mathrm{RB}$ & 361,87 & 103,24 & 42,76 & 1,52 & 0,198 & 794,68 & 2,20 & 0,114 & 0,0220 & 6 \\
\hline MARP & 1099,70 & 193,51 & 46,53 & 1,63 & 0,508 & 2892,81 & 2,63 & 0,095 & 0,0008 & 6 \\
\hline ARF & 652,74 & 152,95 & 74,53 & 1,68 & 0,118 & 1576,28 & 2,41 & 0,104 & 0,0050 & 6 \\
\hline MBRP & 207,39 & 77,41 & 34,65 & 1,51 & 0,173 & 483,52 & 2,33 & 0,107 & 0,0007 & 2 \\
\hline BRP & 433,77 & 123,73 & 34,11 & 1,66 & 0,373 & 973,63 & 2,24 & 0,111 & 0,0016 & 2 \\
\hline
\end{tabular}

Área = área; $\mathbf{P}$ = perímetro; $\mathbf{K c}=$ coeficiente de compacidade; $\mathbf{K f}=$ fator de forma; $\mathbf{L} \mathbf{t}=$ comprimento total de todos os cursos d'água da bacia ou sub-bacia hidrográfica; $\mathbf{D d}$ = densidade de drenagem; l = extensão média do escoamento superficial; S1 = declividade média do curso d'água principal da bacia ou sub-bacia hidrográfica; Ordem = ordem dos cursos d'água; adm = adimensional; BHRP = Bacia Hidrográfica do Rio Preto; ARP = Sub-bacia do Alto Rio Preto; RB = Sub-bacia do Rio do Bananal; MARP = Sub-bacia do Médio Alto Rio Preto; $\mathbf{A R F}=$ Sub-bacia do Alto Rio das Flores; $\mathbf{M B R P}=$ Sub-bacia do Médio Baixo Rio Preto; e BRP = Sub-bacia do Baixo Rio Preto.

e ondulado (Tabela 2). Desse modo, configura-se uma área com alta ocorrência de relevo acidentado juntamente com a dominância de solos com baixa fertilidade e intensa atividade agrícola e pecuária, que intensificam a ocorrência de processos erosivos e de degradação das áreas agricultáveis. A facilidade de instalação do processo erosivo se deveu ao favorecimento da ocorrência de enxurradas, dada a declividade elevada, a ausência de práticas conservacionistas e o uso inadequado do solo, além da sua capacidade de suporte. Quando desprovido de sua vegetação natural, o solo fica exposto a uma série de fatores que tendem a degradá-lo, e a velocidade com que esse depauperamento se processa varia com as características químicas e físicas do próprio solo, com os aspectos climáticos e com a topografia.

Em relação às sub-bacias, observou-se que, em todas essas unidades geográficas, menos de $28 \%$ da área estava compreendida em relevo plano. Apenas as sub-bacias do rio do Bananal e do baixo rio Preto possuíam considerável área em relevo suave-ondulado (em torno de 25\%), enquanto nas restantes acima de $60 \%$ da área estava localizada em relevo ondulado a montanhoso. Chegava-se ao extremo de 36\% de a área da sub-bacia do médio alto rio Preto estar em relevo montanhoso. Mesmo assim, essas áreas têm sido intensamente utilizadas, principalmente com pastagens (REZENDE; RESENDE, 1996).

Essa exploração da terra de modo intensivo mostra a tendência do uso desse recurso até o limite de sua potencialidade, dificultando o crescimento de vegetação como forma de proteção ao solo e diminuindo as possibilidades de equilíbrio entre o solo e o ambiente. Tais fatores favorecem a degradação do solo, com a ocorrência de encrostamento superficial, arraste de partículas orgânicas e minerais e instalação de processos erosivos que podem evoluir para voçorocamentos, ocasionando a queda da capacidade produtiva dos solos e o assoreamento e poluição dos corpos d'água. A atividade pecuária intensa na BHRP, com a super lotação dos pastos mais a construção de estradas mal locadas, também concorreu para as alterações na paisagem (CEIVAP, 2001).

\section{2. Índices morfométricos e hidrografia}

De maneira geral, a BHRP mostrou-se pouco sujeita a enchentes, por apresentar alto valor de coeficiente de compacidade $(\mathrm{Kc}=1,99)$ e fator de forma com valor bastante baixo ( $\mathrm{Kf}=0,068)$. Ou seja, possuía formato alongado e estreito, aliado a uma alta densidade de drenagem ( $\mathrm{Dd}=2,26)$. Segundo Vilela e Matos (1975), o formato da bacia influencia o tempo de concentração, ou seja, o tempo que leva a água dos limites da bacia para chegar à saída. Nesse caso, pode-se dizer que a tendência a enchentes será menor do que ocorreria caso a BHRP tivesse uma forma mais circular. Mas, por se tratar de área bastante extensa, esses índices podem ser considerados de menor precisão, pois na realidade é observada a ocorrência de enchentes na região, em função do relevo acidentado, dos solos rasos e dos intensos processos de desmatamento e de uso da terra. 
A estimativa desses índices e o conhecimento das vazões máximas associadas a determinado risco de ocorrência são importantes para a determinação de áreas sujeitas à inundação, sendo fundamental a adoção de medidas estruturais e não estruturais para controle ou atenuação do efeito das cheias, fornecendo, também, parâmetros necessários ao entendimento de problemas relacionados à erosão e ao depósito de material sólido carreado pelas águas (EUCLYDES; FERREIRA, 2002).

Em relação às sub-bacias (Tabela 2), pode-se afirmar que a sub-bacia hidrográfica do rio do Bananal (RB) estará menos sujeita a enchentes do que as outras, por apresentar alto valor de coeficiente de compacidade $(K c=1,96)$, fator de forma com valor bastante baixo $(\mathrm{Kf}=0,061)$ e alta densidade de drenagem ( $\mathrm{Dd}=2,35)$. Entretanto, a sub-bacia do Médio Alto Rio Preto (MARP) será a mais sujeita a enchentes $(\mathrm{Kc}=1,63$ e $\mathrm{Kf}=0,508)$. Segundo Ray (1963), a densidade de drenagem em dado ambiente climático está relacionada, principalmente, com a resistência à erosão do material presente, aumentando a densidade à medida que diminui a resistência à erosão. Contudo, admite-se que podem existir exceções, e muitas são devidas à natureza dos solos, que se desenvolvem sobre essas rochas (FRANÇA, 1968).

Segundo a hierarquia de Strahler (VILELA; MATOS, 1975) para a BHRP, o sistema de drenagem apresenta grau de ramificação de sexta ordem, levando-se em conta os cursos d'água principais e incluindo córregos e riachos perenes. Considera-se que, quanto mais ramificada a rede, mais eficiente a drenagem. A água precipitada, depois de se ter iniciado o escoamento superficial, vai percorrer uma extensão menor até encontrar um curso d'água (VILELA; MATOS, 1975). Esse percurso é denominado extensão média do escoamento superficial (l). Para a BHRP, foi de $114 \mathrm{~m}$ e para as sub-bacias, variou entre 95 e 114 m, valor considerado pequeno. Extensão de escoamento pequena poderia provocar alagamentos em dias de chuvas intensas em função da menor possibilidade de infiltração da água no solo.

O padrão de drenagem formado pelos cursos d'água da BHRP foi caracterizado como do tipo dendrítico com forte controle estrutural no sentido NE-SW, devido à ocorrência de falhas geológicas, como a que controla o encaixe do rio Paraíba do Sul. Esse controle estrutural também é responsável pela dinâmica das frentes de chuvas, estendendo-se paralelas à linha da costa, ou seja, moldando-se na direção geral NE-SW, paralela à cadeia de montanhas. O padrão de drenagem do tipo dendrítico ocorre em função do tipo de rocha e das estruturas geológicas e tectônicas presentes na bacia. Segundo Soares (2000), esse padrão ocorre em altitudes elevadas, nas quais as rochas de origem oferecem resistência relativamente uniforme à erosão. Em relação à geologia, esse padrão ocorre preferencialmente quando a rocha dos substratos é homogênea, como rochas graníticas ou, ainda, no caso de rochas sedimentares ou metassedimentares com estratos horizontais (RICCOMINI et al., 2001). Em relação às sub-bacias, apenas na sub-bacia do Alto Rio das Flores pôde ser observado o padrão de drenagem mais tendente ao paralelo, fato que pode ser explicado pela geologia local (Complexo Paraíba do Sul) e pela ocorrência de intensa rede de fraturas e falhas, de direção NE-SW.

A declividade média do curso d'água principal (S1) é outro aspecto relevante, pois interfere na velocidade de escoamento da água no curso. Na BHRP, a foz do rio Preto encontrava-se na cota de $340 \mathrm{~m}$, e a nascente situava-se na cota de $2.787 \mathrm{~m}$ de altitude. Mas como o Pico do Itatiaia é isolado nas cabeceiras, devido às elevadas altitudes, para o cálculo desse índice foi considerada a altitude de $800 \mathrm{~m}$, que representa a base desse maciço montanhoso. Nesse intervalo de $224 \mathrm{~km}$ com sentido de corrente de sudoeste-nordeste, o rio Preto apresenta uma diferença de nível de $460 \mathrm{~m}$, com valor de declividade média de $0,0020 \mathrm{~m} / \mathrm{m}$, portanto, segundo Vilela e Matos (1975), mostra tendência a enchentes em razão dessa diferença de altitude.

\section{CONCLUSÕES}

A Bacia Hidrográfica do Rio Preto possuía forma alongada e alta densidade de drenagem. Em condições normais de pluviosidade, espera-se menor ocorrência de cheias. Já o relevo acidentado, associado a solos rasos e desmatamentos frequentes, pode causar cheias.

O predomínio de solos de baixa fertilidade e a intensa atividade agropecuária, associados aos 73,1\% de área com relevo forte-ondulado e montanhoso, podem promover forte degradação por erosão hídrica.

O padrão de drenagem caracteriza-se como do tipo dendrítico, com forte controle estrutural, no sentido nordeste-sudoeste.

A Sub-Bacia Rio do Bananal possuía maior área com relevo suave-ondulado, e seus índices morfométricos indicam menor possibilidade de enchentes, em comparação com as outras sub-bacias.

Revista Árvore, Viçosa-MG, v.35, n.3, p.485-492, 2011 


\section{REFERÊNCIAS}

ALVES, J. M. P.; CASTRO, P.T.A. Influência de feições geológicas na morfologia da bacia do rio Tanque (MG) baseada no estudo de parâmetros morfométricos e análise de padrões de lineamentos. Revista Brasileira de Geociências, v. 33, n. 2, p. 117-127, 2003.

BIE, C.A.; et al. Em direção a operacionalização das informações dos solos para um manejo sustentável das terras. In: ALVAREZ V., V.H.; FONTES, L.E.F.; FONTES, M.P.F. O solo nos grandes domínios morfoclimáticos do Brasil. Sociedade Brasileira de Ciência do Solo, 1996, 335-352.

CEBALLOS, A.; SCHNABEL, S. Hydrological behaviour of a small catchment in the dehesa landuse system (Extremadure, SW Spain). Journal of Hidrology, v.210, p.146-160, 1998.

CEIVAP - Comitê para integração da Bacia Hidrográfica do Paraíba do Sul. Bacia do Paraíba do Sul - Livro da Bacia. Brasília: CEIVAP, 2001. 68p.

\section{EMPRESA BRASILEIRA DE PESQUISA} AGROPECUÁRIA - EMBRAPA. Centro Nacional de Pesquisa de Solos. Sistema Brasileiro de Classificação de Solos. Brasília: 1999. 412p.

ESRI - ENVIRONMENTAL SYSTEMS ESEARCH INSTITUTE. ARC/INFO v.7.1.1. Help on line. Redlands, Califórnia: ESRI, 1997.
EUCLYDES, H.P.; FERREIRA, P.A. Regionalização de vazão máxima, mínima e média de longo período e da curva de permanência para a bacia do Alto e Médio São Francisco. In: Tecnologia para elaboração de projetos hidroagrícolas em bacias hidrográficas. Viçosa: UFV- RURALMINAS, 2002.142p. (Boletim Técnico, n. 6).

FAO - FOOD AND AGRICULTURE ORGANIZATION OF THE UNITED NATIONS. Water and sustainable agricultural development. Rome: FAO, 1990. 48p.

FRANÇA, G.V. Interpretação fotográfica de bacias e de redes de drenagem de 3 séries de solos da Fazenda Ipanema, município de Araçoiaba da Serra (SP).1968. 150p. Tese de Doutorado ESALQ, Piracicaba 1968.

GARCEZ, L.N.; ALVAREZ, G.A. Hidrologia. São Paulo: Ed. Edgard Blucher Ltda. 1988.

RICCOMINI, C.; GIANNINI, P.C.F; MANZINI, F. Rios e processos aluviais. In: TEIXEIRA, W.; et al. Decifrando a Terra. São Paulo: Oficina de Textos. 2000. 191-214.

RAY, R.G. Fotografias aéreas na interpretação e mapeamento de solos. São Paulo, Instituto Geográfico e Geológico, 1963. 163p.

SOARES, J.V. Curso de introdução à hidrologia florestal. São José dos Campos-SP: INPE. 2000. 78p.

VILLELA, S.M.; MATTOS, A. Hidrologia aplicada. São Paulo: Mcgraw Hill, 1975. 250p

WANG, X.; YIN, Z.Y. A comparison of drainage networks derived from digital elevation models at two scales. Journal of Hidrology, v.210, p.221-241, 1998. 